\title{
IDENTIFICATION AND ASSESSMENT OF COUNTRY RISKS FOR THE DEVELOPMENT OF CONVERGENT TECHNOLOGIES ${ }^{1}$
}

\author{
Marina E. Buyanova \\ Volgograd State University, Volgograd, Russian Federation
}

\begin{abstract}
The speed of emergence and development of new technologies is so high that it becomes more and more difficult to predict their impact on economy and society. At the same time, new technologies do not develop in isolation; they interact and actively influence each other, generating synergistic effects, which actualizes the need for scientific knowledge of the consequences, as well as the conditions and factors for the emergence of risks and methods of managing them. The aim of the work is to substantiate a theoretical and methodological approach to identifying and assessing the risks of the development of convergent technologies and their consequences in life. The research is based on the methodology of dialectical, system and evolutionary and institutional approaches to the study of the risks of the development of social and economic systems, the theory of factors of production, economic development, and the economic mechanism. This paper examines the conditions and social and economic prerequisites for the new industrial revolution in Russia, as well as the risks that arise in this process. The author carries out the analysis of constructive and destructive economic and social consequences of NBIC technologies rapidly developing in all countries of the world. In conclusion, the author proposes priority directions of the regulation of social and economic processes in the country, ensuring competitive, sustainable and safe development.

Key words: technological structure, Industrial Revolution 4.0, convergent technologies, NBIC technologies, risks of introducing convergent technologies, country risks, risk assessment indicators.
\end{abstract}

Citation. Buyanova M.E. Identification and Assessment of Country Risks for the Development of Convergent Technologies. Vestnik Volgogradskogo gosudarstvennogo universiteta. Ekonomika [Journal of Volgograd State University. Economics], 2021, vol. 23, no. 1, pp. 40-51. (in Russian). DOI: https://doi.org/10.15688/ek.jvolsu.2021.1.3

\section{ИДЕНТИФИКАЦИЯ И ОЦЕНКА СТРАНОВЫХ РИСКОВ РАЗВИТИЯ КОНВЕРГЕНТНЫХ ТЕХНОЛОГИЙ ${ }^{1}$}

\author{
Марина Эдуардовна Буянова \\ Волгоградский государственный университет, г. Волгоград, Российская Федерация
}

\begin{abstract}
Аннотация. Скорость возникновения и развития новых технологий так велика, что становится все труднее прогнозировать их воздействие на экономику и социум. При этом новые технологии не развиваются изолированно, а взаимодействуют и активно влияют друг на друга, порождая синергетические эффекты, что актуализирует необходимость научного познания последствий, а также условий и факторов возникновения рисков и способов управления ими. Целью работы является обоснование теоретико-методического подхода

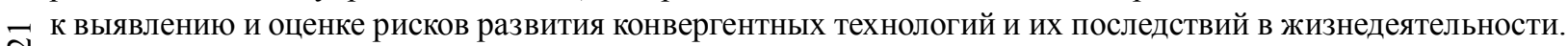
В основу исследования положены методологии диалектического, системно-эволюционного и институционального подходов к изучению рисков развития социально-экономических систем, теории факторов производства, экономического развития, хозяйственного механизма. В данной работе исследуются условия и со๘ циальные и экономические предпосылки новой промышленной революции в России, а также риски, возникающие в данном процессе. Проведен анализ конструктивных и деструктивных экономических и социальных последствий стремительно развивающихся во всех станах мира NBIC-технологий. Автор полагает, что потен(?) циальные риски конвергентных технологий - это риски, которые не могут быть спрогнозированы, оценены
\end{abstract}


и идентифицированы, поскольку научные знания в сфере их возникновения практически отсутствуют. Следовательно, оценка рисков конвергентных технологий представляет определение возможных сценариев (как положительных, так и отрицательных) о событии (проектировании, разработке, внедрении, использовании технологии). Для этого предложена система индикаторов оценки обеспеченности и вовлеченности в воспроизводственные процессы факторов социально-экономического развития, с помощью которых становится возможным выявление потенциальных страновых рисков развития конвергентных технологий. В заключение предложены приоритетные направления регулирования социально-экономических процессов в стране, обеспечивающие конкурентоспособное, устойчивое и безопасное развитие.

Ключевые слова: технологический уклад, Промышленная революция 4.0, конвергентные технологии, НБИК-технологии, риски внедрения конвергентных технологий, страновые риски, индикаторы оценки рисков.

Цитирование. Буянова М. Э. Идентификация и оценка страновых рисков развития конвергентных технологий // Вестник Волгоградского государственного университета. Экономика. - 2021. - Т. 23, № 1. C. 40-51. -DOI: https://doi.org/10.15688/ek.jvolsu.2021.1.3

\section{Введение}

В современном мире технологии становятся главной детерминантой развития. Скорость возникновения и распространения новых технологий так велика, что становится все труднее прогнозировать их влияние на жизнедеятельность человека. Как отмечает В.К. Степанюк, вновь создаваемые технологии опережают и направляют науку, создавая проблемы с осознанием последствий своего развития [Степанюк, 2017].

Доминирующими областями, в которых ускоренными темпами рождаются и развиваются новые технологии, являются информационные технологии, биотехнологии, нанотехнологии и когнитивная наука. При этом такие технологии не развиваются изолированно, они взаимодействуют, взаимопересекаются и активно влияют друг на друга, порождая синергетические эффекты. Подобное явление взаимоусиления технологий получило название NBIC-конвергенции [Белянцев, 2013].

Технологическая конвергенция (от лат. «convergo» - приближаюсь, схожусь) - это синергетическая комбинация научно-технологических областей: N - нано; В - био; I - инфо; C - когнито, развивающихся наиболее быстрыми темпами, результаты которой проявляются в междисциплинарных научно-исследовательских разработках на стыке различных областей науки и технологий [Аматова, 2014].

Поскольку NBIC-конвергенции отводится роль «основного катализатора техногенной модификации технологической и социальной среды» [Степанюк, 2017], актуальными задачами являются осмысление и глубокий ана- лиз результатов и последствий достижений человечества в сфере высоких технологий. Эти результаты во многом характеризуются высокими уровнями динамичности и неопределенности, а также многовариантными эффектами как позитивного, так и негативного характера, порождающие многочисленные угрозы и риски устойчивого, безопасного развития социохозяйственных систем.

Таким образом, основной задачей, требующей решения, становится выявление, оценка и снижение рисков внедрения конвергентных технологий и осмысление их последствий в жизнедеятельности.

\section{Материалы и методы}

Основоположниками концепции смены технико-технологических укладов, теории которых заложены в ходе осмысления влияния конвергентных технологий на современные процессы, происходящие в обществе, являются С. Глазьев, Д. Львов, Дж. Рифкин, К. Шваб, О. Иншаков, Г. Клейнер, К. Перес, С. Кузнец, Й. Шумпетер.

Теоретико-методические основы исследования рисков социально-экономического развития заложены в классических трудах Д. Бьюкенена, Ф. Найта, О. Моргенштерна, А. Пигу и др. и получили дальнейшее развитие в работах как зарубежных исследователей Т. Бачкаи, П. Друкера, Г. Марковица, так и в трудах отечественных ученых - экономистов В. Абчука, П. Грабового, Р. Качалова, Р. Нижегородцева, А. Татаркина и др.

Исследование основывается на методологии диалектического, системно-эволюционного 
и институционального подходов к изучению рисков развития социально-экономических систем, теории факторов производства, экономического развития, хозяйственного механизма.

При реализации задач, поставленных в данной работе, применялись общенаучные методы, системный, историко-логический, статистико-вероятностный подходы; а также инструменты дескриптивного и компаративного анализа.

\section{Угрозы и риски развития конвергентных технологий}

Развитие конвергентных технологий, присущих современному уровню науки, экономики и производства происходит в условиях становления начальной фазы четвертой промышленной революции, которая, по сути, и представляет собой слияние в едином процессе физических, цифровых и биологических технологий, порождая абсолютно новое качество развития [Рифкин, 2014].

Основой Промышленной революции 4.0 выступают создаваемые умные фабрики (smart factory) [Germany Trade\&Invest]; интернет вещей, точнее, промышленный интернет вещей (industrial internet of things), обеспечивающий взаимодействие автономных технических устройств и контроль за ними со стороны человека [The Industrial Internet ..., 2018]; встроенные датчики и системы обработки получаемых от них больших массивов информации (big data). В сфере производственных технологий широкое применение находит 3Dпринтирование - система послойного наращивания исходных материалов, опирающаяся на использование трехмерных компьютерных моделей готового изделия.

Один из основоположников концепции развития «Промышленная революция 4.0» Клаус Шваб дает следующее определение четвертой промышленной революции: «Распространяя технологию “умных заводов”, четвертая промышленная революция создает мир, в котором виртуальные и физические системы производства гибко взаимодействуют между собой на глобальном уровне» [Шваб, 2016, с. 10-12]. Одновременно рождаются прорывные технологии в самых различных областях: от «расшифровки информа- ции, записанной в человеческих генах, до нанотехнологий: от возобновляемых энергоресурсов до квантовых вычислений» [Шваб, 2016 , с. 12]. Синтез и взаимодействие этих технологий в физических, цифровых и биологических доменах составляют фундаментальное отличие четвертой промышленной революции от всех предыдущих.

Так, четвертая промышленная революция ведет к качественным преобразованиям во всех аспектах социально-экономических отношений. Благодаря цифровизации экономических и производственных процессов, внедрению технологий искусственного интеллекта, больших данных, Интернета вещей и Интернета ценностей (блокчейн), передовой робототехники обеспечиваются автоматизация и взаимосвязанность, меняющие саму парадигму организации и эффективности производства [Спартак, 2018, с. 15].

Следует согласиться с С.Д. Бодруновым, который отмечает, что принципиально новым отличием Промышленной революции 4.0 является «широкая интеграция различных по “родовому” происхождению технологий» [Бодрунов, 2019, с. 10], образующаяся благодаря синтезу нано-, био-, информационных и когнитивных технологий-NBIC-конвергенция [Converging Technologies for Improving Human Performance, 2002].

Основной ожидаемый «эффект» для стран, которые создают условия для осуществления четвертой промышленной революции, - это «запуск экономического развития», то есть обеспечение прироста темпов развития экономики посредством получения дополнительных конкурентных преимуществ, к которым можно отнести - значительный рост производительности труда, снижение издержек производства и обращения, появление новых рынков ресурсов и сбыта, масштабные изменения рынка труда. Этот «эффект» будет тем заметнее и ощутимее, чем быстрее прогрессируют информационные технологии, биотехнологии, нанотехнологии и когнитивная наука.

Именно поэтому экономики ведущих стран мира изыскивают и затрачивают значительные ресурсы на научно-технологическое и инновационное развитие, основанное на NBIC-конвергенции. 
M.Э. Буянова. Идентификация и оценка страновых рисков развития конвергентных технологий

Конвергенция нано-, био-, инфо- и когнитивных технологий вместе с развитием 3D-принтирования, промышленного интернета, роботизации, созданием и использованием искусственного интеллекта и рядом других инновационных трендов должны привести к очередному массовому «созидательному разрушению» в производстве средств производства [Толкачев и др., 2019]. В связи с этим в настоящее время одной из тенденций является стремление ведущих стран мира обеспечить критическую концентрацию научно-инженерной базы и защитить нарождающиеся высокотехнологичные отечественные отрасли и собственное лидерство (примером тому может служить начавшаяся в 2018 г. торговая война между США и Китаем).

Однако следует понимать, что NBIC-технологии влекут как конструктивные, так и деструктивные экономические и социальные последствия, предсказать которые не только трудно, но иногда и невозможно.

Первая группа угроз имеет антропологический характер и связана с открытиями и разработками нано-, биотехнологий, позволяющими значительно продвинуться вперед в области лечения различных заболеваний на генном уровне, значительно увеличить продолжительность жизни.

Многие страны начали реализацию специальных программ по улучшению природы человека на базе NBIC-конвергенции.

Например, «Converging Technologies for Improving Human Performances», CШA; «Converging Technologies for European Knowledge Society», Евросоюз, проект образованного в России общественного движения «Россия 2045» и международного научно-исследовательского центра киборгизации - «Создание искусственного тела и подготовка человека к переходу в него» [Аматова, 2014].

Вместе с тем расшифровка генома человека, возможность изменения как его физических, так и умственных возможностей продуцирует риск создания нового вида оружия, несущего угрозу всему человечеству.

Конвергенция информационных и когнитивных технологий используется для усиления человеческого интеллекта [Качалов и др., 2019]. Они пока еще дополняют естественные способности человека в сборе и использова- нии информации, являясь мощным образовательным ресурсом, но в скором времени элементы искусственного интеллекта будут дополнять разум человека с использованием прямых интерфейсов «мозг-компьютер».

Но здесь необходимо учитывать возможности негативного влияния интернет-ресурсов на сознание и мировоззрение людей, особенно молодежи, то есть возникают риски превращения интернета в механизм управления сознанием в деструктивных целях.

Развитие способностей человека также формирует предпосылки усиления дифференциации людей по возможностям воспользоваться результатами новейших разработок.

Вторая группа угроз связана с неравномерным распределением био-, нано-, информационных ресурсов среди стран. Так, А.Е. Белянцев в качестве примера приводит ситуацию в ядерной сфере, связанную с режимом нераспространения, отмечая, что страны, отставшие в развитии новых технологий, не будут заинтересованы в контроле, а также ограничении использования этих технологий, что может привести опять-таки к угрозе человечеству [Белянцев, 2013].

Помимо этого, следует заметить, что более богатые страны получают шанс воспользоваться преимуществами новейших технологий, что еще больше усилит уровень социально-экономического неравенства между странами, продуцируя риски возникновения межстрановых противоречий и конфликтов.

В отдельную группу, влекущую значимые риски как социального, так и экономического характера, следует включить структурные и функциональные изменения рынка труда.

К таким рискам следует отнести: возрастающее неравенство по доходам между отдельными группами занятого и незанятого населения внутри стран вследствие изменений структуры рынка труда; значительный рост безработицы в отдельных сегментах рынка труда вследствие автоматизации и роботизации труда и исчезновения многих профессий; ускорение процесса устаревания знаний человека и необходимость постоянного обучения в течение всей жизни.

По мнению исследователей, риски конвергентных технологий правомерно отнести к рискам высокого и катастрофического уров- 
ней, так как их проявление охватывает всю жизнедеятельность человека [Pukala, 2016].

Потенциальные риски конвергентных технологий - это риски, которые не могут быть спрогнозированы, оценены и идентифицированы, поскольку научные знания в сфере возникновения риска отсутствуют. Следовательно, оценка рисков конвергентных технологий представляет определение возможных сценариев (как положительных, так и отрицательных) о событии (проектировании, разработке, внедрении, использовании технологии) [Аршинов и др., 2016].

Понимание сущности рисков конвергентных технологий опирается на фундаментальные основы теории систем, согласно которой потеря системой устойчивости, нарушение порядка являются источником рисков функционирования системы, а изменения социальноэкономических систем, их эволюция (в особенности революционные сдвиги) есть мощные генераторы рисков и опасностей. В свою очередь, их накопление в ходе функционирования системы является источником, провоцирующим дальнейшие изменения [Буянова, 2007, c. 171-175].

Исходя из этого, риск обладает двойственной природой: с одной стороны, это деструктивная сила, с другой - сила, несущая заряд перемен (изменений), без которых невозможно прогрессивное развитие общества.

Кроме того, следует различать позитивные (несущие социально-экономической системе положительный заряд) и негативные (придающие социально-экономической системе отрицательный импульс) риски.

Положительно заряженные риски в конечном результате способствуют совершенствованию системы, еепозитивной трансформации, переходу на качественно новый уровень развития. Отрицательно заряженные элементы (опасности) вызывают деструктивные процессы в системе, вплоть до ее разрушения.

Все сказанное подтверждается высочайшей степенью неопределенности результатов разработки и использования конвергентных технологий для человека, общества, экономики, государства, связанной с двойственным итогом события в рамках развития конвергентных технологий: с одной стороны, положительный импульс и динамика начинания (со- здания новой технологии), с другой - потенциальный риск использования данной технологии в деструктивном направлении (либо ее неожиданный негативный результат).

\section{Идентификация и выявление рисков развития конвергентных технологий}

\section{в условиях становления}

\section{Промышленной революции 4.0}

Ключевыми факторами преобразований в экономике, бизнесе, обществе в целом на основе NBIC-конвергенции являются цифровые технологии, генерация знаний, создание благоприятных условий для развития технологий и готовности к принятию инноваций.

Следовательно, преимущества для вхождения в четвертую промышленную революцию и формирования новой структуры хозяйствования получает тот субъект, который обладает ресурсами, являющимися ключевыми для развития ядра нового технологического уклада.

Для России этот переход должен быть реализован в ее научно-технической и социально-экономической политиках, направленных на формирование и поддержку инновационной способности российского общества, посредством реализации целевых программ развития, наращивания ресурсной базы и инфраструктуры для подготовки высококвалифицированных кадров, реализации инновационных проектов, опирающихся на традиционные ценности и развитые институты.

Перечисленные выше ключевые факторы развития NBIC-конвергенции позволяют сформировать подход к идентификации и выявлению потенциальных страновых рисков развития конвергентных технологий.

Подход основан на концепции «ядра развития», согласно которому функционирование социоэкономической системы представляет социально организованный и институциональный процесс взаимодействия факторов (человеческого, технико-технологического, природно-ресурсного, институционального, организационного, информационного), которые являются его движущими силами [Иншаков, 2003].

Наряду с воспроизводством и видоизменением условий, ресурсов и факторов система продуцирует и накапливает риски, позитив- 
M.Э. Буянова. Идентификация и оценка страновых рисков развития конвергентных технологий

но или негативно влияя при этом на объем и структуру общественного производства, возможности экономики удовлетворять меняющиеся общественные потребности в условиях конвергенции технологий.

Необеспеченность, несбалансированность и преобладание некомплементарных комбинаций факторов развития следует рассматривать как потенциальные риски развития системы, а динамическая сбалансированность и преобладание комплементарных комбинаций факторов развития означает возможность вполне гармоничного развития технико-технологического, научного, инновационного потенциалов на основе конвергентых технологий и их внедрения в экономику [Буянова, 2012].

Количественными индикаторами потенциальных рисков конвергентных технологий могут выступать показатели, используемые в мировой практике для оценки процессов и явлений, характеризующих готовность национальных экономик к четвертой промышленной революции.

Индекс иифровой конкурентоспособности (Digital Competitiveness Index, IMD) предназначен для мониторинга цифровой трансформации и оценки страновой технологической инфраструктуры. Использование данного индикатора позволяет провести ранжирование стран по готовности и способности национальных экономик внедрять и разрабатывать цифровые технологии, ведущие к трансформации государственного управления, бизнес моделей и общества в целом [Государство. Бизнес ..., 2020].

В основу методологии положена оценка цифровой среды на уровне как частных, так и государственных компаний по трем группам факторов:

- знания (в разрезе таких критериев, как кадры, научный потенциал, образование и повышение квалификации) по результатам оценки страны выстраиваются в порядке убывания качества обучения, образования, науки;

- технологии (в разрезе таких критериев, как законодательная база, капитал, технологическая инфраструктура), по результатам оценки страны распределяются в соответствии с развитием интернет- и коммуникационных технологий, финансовым капита- лом в IT-сфере и состоянием институциональной среды;

- готовность к обновлениям (оцениваемая по критериям восприимчивости, адаптации к новым технологиям и их интеграции), по результатам оценки высокие рейтинги принадлежат странам, готовым использовать цифровую трансформацию.

Индекс глобальной конкурентоспособности (Global Competitiveness Index, GCI) предназначен для оценки «благоприятности» условий ведения конкурентоспособного бизнеса в стране. Для этого государства оцениваются с применением свыше 300 показателей, с помощью которых становится возможным провести оценку важнейших аспектов состояния экономики и условий ведения бизнеса. Они укрупнено могут быть объединены в четыре группы: индикаторы оценки состояния экономики; эффективности функционирования правительства; состояния предпринимательской среды; сформированности инфраструктуры [Индекс глобальной конкурентоспособности ...].

Одним из важнейших аспектов исследования глобальной конкурентоспособности страны является то, что в процессе ее оценки выявляются риски факторов развития системы. Так, можно идентифицировать институциональные риски, формируемые в результате неэффективного управления государственными финансами, высокой инфляции, плохо отлаженной системой защиты прав интеллектуальной собственности, неразвитой судебной системой. Наряду с институциональными факторами рисков определяющее значение могут иметь образование и повышение квалификации рабочей силы, постоянный доступ к новым знаниям и технологиям. Кроме того, выявляются риски дифференциации «стартовых» условий функционирования национальных экосистем.

При этом следует подчеркнуть, что ни один из факторов не может обеспечить конкурентоспособностью национальной экономики в отдельности, они должны оцениваться только в комплексе и взаимообусловленности.

Так, если, например, неэффективно функционируют рынок труда, институциональная инфраструктура системы образования, то увеличение расходов на образование не сможет 
существенно улучшить состояние человеческого фактора. Оптимизация контроля над государственными финансами даст результат в виде, например, улучшения макроэкономической среды, только в случае обеспечения «прозрачности» управления финансовой системой, отсутствия коррупции и т. п.

Именно поэтому анализ глобального индекса конкурентоспособности может выступать «оценочным» индикатором выявления потенциальных рисков необеспеченности, несбалансированности и некомплементарности факторов развития системы.

Глобальный индекс инновациий (The Global Innovation Index WIPO) - предназначен для оценки уровня развития инновационного потенциала и условий его реализации в различных странах. Рассчитывается по методике Международной бизнес-школы INSEAD, Франция [Глобальный индекс инноваций ...].
В основу методологии положена оценка инновационной среды по двум группам факторов:

- располагаемые ресурсы и условия для проведения инноваций (в разрезе таких критериев, как институты, человеческий капитал и научные исследования, инновационная инфраструктура, развитие внутреннего рынка, формирующего спрос на инновации, развитие бизнеса);

- результаты осуществления инноваций (в разрезе таких критериев, как развитие технологий, результаты творческой деятельности и экономика знаний).

Результаты оценки готовности национальных экономик стран мира к четвертой промышленной революции представлены в таблице.

Результаты анализа индекса цүифровой конкурентоспособности показали, что Международная цифровая конкурентоспособность

Таблица

Система показателей оценки готовности национальных экономик к четвертой промышленной революции, 2019 г.

\begin{tabular}{|c|c|c|c|}
\hline \multirow[b]{2}{*}{ Страна } & \multicolumn{3}{|c|}{ Промышленная революция 4.0 - показатели «готовности» } \\
\hline & $\begin{array}{c}\text { Индекс цифровой } \\
\text { конкурентоспособности, } \\
\text { баллы } 1-100\end{array}$ & $\begin{array}{c}\text { Индекс глобальной } \\
\text { конкурентоспособности, } \\
\text { баллы } 1-100\end{array}$ & $\begin{array}{c}\text { Глобальный } \\
\text { индекс инноваций, } \\
\text { баллы } 1-100\end{array}$ \\
\hline США & 100,0 & 83,3 & 61,7 \\
\hline Сингапур & 99,4 & 84,8 & 58,4 \\
\hline Швеция & 96,0 & 81,2 & 63,7 \\
\hline Дания & 95,2 & 81,2 & 58,4 \\
\hline Швейцария & 94,6 & 82,3 & 67,2 \\
\hline Финляндия & 93,7 & 80,2 & 59,8 \\
\hline $\begin{array}{l}\text { Республика Корея } \\
\text { (Южная Корея) }\end{array}$ & 91,3 & 79,6 & 56,6 \\
\hline Канада & 90,8 & 79,6 & 53,9 \\
\hline Австралия & 88,9 & 78,7 & 50,3 \\
\hline $\begin{array}{l}\text { Соединенное } \\
\text { Королевство }\end{array}$ & 88,7 & 81,2 & 61,3 \\
\hline Германия & 86,2 & 81,8 & 58,2 \\
\hline Китай & 84,3 & 73,9 & 54,8 \\
\hline Япония & 82,7 & 82,3 & 54,7 \\
\hline Франция & 82,5 & 78,8 & 54,2 \\
\hline Казахстан & 72,6 & 62,9 & 31,0 \\
\hline Россия & 70,4 & 66,7 & 37,6 \\
\hline Италия & 67,9 & 71,5 & 46,3 \\
\hline Индия & 65,0 & 61,4 & 37,5 \\
\hline Южная Африка & 60,8 & 62,4 & 34,0 \\
\hline Мексика & 60,4 & 64,9 & 36,1 \\
\hline Турция & 59,8 & 62,1 & 36,9 \\
\hline Беларусь & н/д & Н/д & 32,1 \\
\hline Украина & 55,3 & 57,0 & 37,4 \\
\hline
\end{tabular}

Примечание. Составлено по: [Государство. Бизнес ... ; Дата сет ... ; Индекс глобальной конкурентоспособности ...]. 
России улучшилась в среднем на две позиции: до 38-го места из 63 возможных (в сравнении с рейтингами периодов 2016-2018 гг.), но присутствует значительное отставание от стран, лидирующих по этому показателю (США, Сингапур, Швеция, Дания, Швейцария, Финляндия) (см. таблицу).

Если же смотреть по трем составляющим этот показатель факторам (знания, технологии, готовность к обновлениям), то по «знаниевому» компоненту Россия занимает 24-ю позицию (из 63 стран рейтинга), что свидетельствует о высоком уровне развития образования и науки; по состоянию IT-сферы и институциональной инфраструктуры, обеспечивающей ее функционирование, Россия занимает лишь 43-е место; по уровню готовности к цифровой трансформации - 51-е место в рейтинге [Государство. Бизнес ...].

Именно составляющие компоненты фактора «готовность к будущей трансформации» в большей степени продуцируют риски соответствия / несоответствия условиям Промышленной революции 4.0 - и здесь есть определенные успехи России по сравнению с предыдущим периодом.

Так, по внедрению роботов РФ заняла 30-ю строчку, по применению системы электронного правительства - 28-ю, по использованию больших данных - 31-ю. Вместе с тем по таким элементам, как отношение к глобализации, степень адаптивности и динамичности бизнеса, трансферы технологий, незаконные операции в области программного обеспечения, Россия заняла - 60-е, 57-е и 53-е места соответственно, что значительно усиливает факторы риска технологического отставания от ведущих (в этой сфере) держав мира [На две строчки ..., 2019].

Индекс глобальной конкурентоспособности, как отмечалось выше, позволяет оценить потенциал развития, исходя из стартовых условий национальных экономик.

Показательно, что в 2019 г. по этому индикатору России удалось сохранить 43-е место в рейтинге среди 141 страны по сравнению с предшествующим периодом (лидерами, так же как и по предыдущему индикатору, являются - Сингапур (1-е место), США, Швеция, Дания, Швейцария, Финляндия). Кроме того, в группу лидеров уверенно вошли Гер- мания и Япония, а среди стран БРИКС лидирует Китай, который в общем рейтинге занимает 28-е место [Россия сохранила 43-е место ...] (см. таблицу).

Сохранению Россией достаточно стабильного уровня глобальной конкурентоспособности способствовали низкий уровень инфляции, устойчивое состояние финансов государства (по одному из составляющих элементов «макроэкономическая стабильность»Россия заняла 43-е место).

Кроме того, достаточно высокую оценку имеют: уровень инновационного потенциала (32-е место); внедрение информационных технологий (22-е место); уровень развития высшего образования и профессиональной подготовки (54-е место); эффективность рынка труда (62-е место), что свидетельствует о тенденции снижения рисков таких факторов конкурентоспособности и развития, как технико-технологический, человеческий, организационный и информационный.

Этому способствовали улучшение качества научно-исследовательских институтов, стабильный рост расходов на НИОКР в общем объеме ВВП, повсеместное внедрение информационно-коммуникационных технологий.

Вместе с тем Россия оказалась в нижней половине рейтинга по таким важнейшим критериям, как состояние и перспективы развития общественных институтов (74-е место); эффективность рынка товаров и услуг (87-е место); развитость финансовой системы (95-е место), что свидетельствует о тенденции устойчивого повышения институциональных рисков развития.

Что касается позиционирования стран по глобальному индексу инноващий, иллюстрирующему, как отмечалось, ресурсную обеспеченность инновационной деятельности и ее результаты, то уже восьмой год подряд по данному индикатору лидирует Швейцария (в рейтинге 2019 г. участвовало 129 стран).

Эксперты единодушно отмечают успехи Китая, который за 10 лет добился существенного роста этого показателя, взяв курс на развитие инновационного потенциала мирового значения. В 2008 г. страна занимала только 37-е место, в 2019 г. - поднялась до 17-го места [Глобальный инновационный индекс - 2019]. 


\section{ЭКОНОМИЧЕСКАЯ ТЕОРИЯ}

Россия показала рост значения этого индикатора, заняв 46-е место в рейтинге, поднявшись на две позиции по сравнению с предыдущим периодом (см. таблицу).

Однако необходимо отметить две разнонаправленные тенденции в инновационной составляющей развития национальной экономики.

С одной стороны, мы видим стабильное улучшение показателей «ресурсной» составляющей инновационной деятельности. Так, высокое развитие человеческого капитала и науки (23-е место в рейтинге); развитие бизнеса, особенно быстрые темпы роста наукоемких отраслей (35-е место); развитие технологий и экономики знаний (47-е место), отражающиеся в увеличении числа патентных заявок на изобретения и полезные модели и улучшении качества научных публикаций, позволили нашей стране существенно улучшить свою позицию (Россия поднялась на 11 пунктов в рейтинге) по субиндексу «ресурсы инноваций».

С другой стороны, по-прежнему нестабильны и неэффективны нормативно-правовыеусловия инновационной деятельности (95-е место); политическая ситуация (91-е место); качество регуляторной среды (103-е место); низкую оценку получила экологическая устойчивость и система экологического менеджмента и ее соответствие требованиям стандарта ISO 9001 (112-е место); использование венчурного капитала (77-е место) и др.

Это отразилось в общем итоге на субиндексе «результативность инновационной деятельности» - Россия потеряла 11 пунктов в рейтинге.

Так, вновь (как и при оценке рисков глобальной конкурентоспособности) мы можем констатировать высокий уровень риска обеспеченности и результативности институционального фактора развития.

Обобщив позитивный опыт ведущих стран, можно вывести основные направления, минимизирующие риски отставания в сфере инновационного развития. Это наращивание инновационного потенциала; расширение и поддержка наукоемких отраслей, следствием развития которых является появление многополярных инноваций; развития инфраструктуры коммерциализации научно-технических разработок.

\section{Заключение}

Таким образом, по результатам проведенного компаративного и дескриптивного анализа можно сделать следующие выводы.

Уровень технико-технологического развития страны, ее научный потенциал, обеспеченность информационными ресурсами придают «положительный заряд» развитию экономики, обеспечивая позитивный потенциал ее готовности к будущему.

Наиболее сильное положительное влияние на процессы преобразований оказывают знания, человеческий капитал, отрицательное - готовность к обновлениям.

Однако, несмотря на то что Россия достаточно быстрыми темпами развивает свой инновационный потенциал на фоне мирового уровня, страна значительно отстает от развитых и многих быстроразвивающихся государств практически по всем ключевым параметрам, характеризующим эффективность использования ресурсов и степень воздействия результатов научно-технической и инновационной деятельности на экономику и общество [Глазьев, 2016].

Следовательно, стратегическими императивами, обеспечивающими устойчивое, конкурентоспособное и безопасное развитие национальной экономики, являются: цифровизация отдельных рынков и отраслей (умный город, цифровое здравоохранение и образование, госуправление и т. д.); активизация частно-государственного партнерства в сфере внедрения цифровых технологий во всех ведущих сферах экономики; поддержка научных исследований и разработок посредством обеспечения координации усилий ключевых игроков рынка, стимулирование взаимодействия между вузами, производственными предприятиями и научными организациями; создание условий для развития законодательной регуляторной среды.

\section{ПРИМЕЧАНИЕ}

${ }^{1}$ Исследование выполнено при финансовой поддержке РФФИ и Администрации Волгоградской области в рамках научного проекта № 19-410340014 p_a «Совершенствование механизмов и инструментов экономического роста регионов РФ в условиях развития конвергентных технологий». 
The reported study was funded by Russian Foundation for Basic Research and the government of Volgograd region according to the research project "Improvement of mechanisms and instruments of economic growth in Russian regions in terms of development of convergent technologies", project No. 19-410-340014p_a.

\section{СПИСОК ЛИТЕРАТУРЫ}

Аматова, Н. Е. Социальные последствия внедрения NBIC-технологий: риски и ожидания /Н. Е. Аматова // Universum: общественные науки. 2014. - № 8 (9). - Электрон. текстовые дан. Режим доступа: http://7universum.com/ru/ social/archive/item/1549 (дата обращения: 22.01.2020). - Загл. с экрана.

Аршинов, В. И. Сложностный мир и его наблюдатель. Часть вторая / В. И. Аршинов, Я. И. Свирский // Философия науки и техники. - 2016. T. 21, № 1.- C. 78-91.

Белянцев, А. Е. NBIC-технологии как сфера международного взаимодействия / А. Е. Белянцев // Вестник Нижегородского университета им. Н.И. Лобачевского. - 2013. - № 6 (1). С. $350-356$.

Бодрунов, С. Д. Ноономика: онтологические тезисы / С. Д. Бодрунов // Экономическое возрождение России. - 2019. - № 4 (62). - С. 9-16.

Буянова, М. Э. Оценка риска социально-экономического развития регионов Юга России (факторный подход) / М. Э. Буянова // Вестник Волгоградского государственного университета. Серия 3, Экономика. Экология. - 2012. № 1 (20). - С. 85-94.

Буянова, М. Э. Риски развития макрорегионального хозяйства: выявление и регулирование / М. Э. Буянова. - Волгоград : Изд-во ВолГУ, 2007. $-540 \mathrm{c}$.

Глазьев, С. Ю. Экономика будущего. Есть ли у России шанс? / С. Ю. Глазьев. - М. : Книжный мир, 2016. -600 c.

Глобальный индекс инноваций: исследование стран и регионов - 2019. - Электрон. текстовые дан. Режим доступа: https:/gtmarket.ru/ratings/ global-innovation-index/info (дата обращения: 15.12.2019). - Загл. с экрана.

Глобальный инновационный индекс - 2019 // Исследование Высшей школы экономики. Электрон. текстовые дан. - Режим доступа: https://issek.hse.ru/news/299608238.html (дата обращения: 20.01.2020). - Загл. с экрана.

Государство. Бизнес. ИТ 2020: Россия в ИТ-рейтингах. - Электрон. текстовые дан. - Режим доступа: http://www.tadviser.ru/index.php (дата обращения: 15.12.2019). - Загл. с экрана.
Дата сет "Большие данные современной мировой экономики: цифровая платформа для интеллектуальной аналитики - 2020" // Институт научных коммуникаций. - Электрон. текстовые дан. - Режим доступа: https://www.archilab. online/data2/data-set-po-mirovoj-ekonomike (дата обращения: 20.01.2020). - Загл. с экрана.

Индекс глобальной конкурентоспособности (2020). Гуманитарная энциклопедия: Исследования, Центр гуманитарных технологий, 20062020 (последняя редакция: 08.02.2020). - Электрон. текстовые дан. - Режим доступа: https:// gtmarket.ru/ratings/global-competitivenessindex/info (дата обращения: 15.02.2020). - Загл. с экрана.

Иншаков, О. В. «Ядро развития» в контексте новой теории факторов производства / О. В. Иншаков // Экономическая наука современной России. - 2003. - № 1. - С. 11-26.

Качалов, Р. М. Оценка риска реализации инновационных проектов предприятий с помощью искусственных нейронных сетей / Р. М. Качалов, Ю. Слепцова, Я. В. Шокин // Вестник Волгоградского государственного университета. Экономика. - 2019. - № 4 (17). - С. 171-179.

На две строчки ближе к будущему: Россия продвинулась в рейтинге цифровой конкурентоспособности // Коммерсантъ. - 2019. 27 сент. (№ 176). - С. 2.

Рифкин, Дж. Третья промышленная революция: Как горизонтальные взаимодействия меняют энергетику, экономику и мир в целом : пер. с англ. / Дж. Рифкин. - М. : Альпина нон-фикшн, 2014. $-410 \mathrm{c}$.

Россия сохранила 43-е место в рейтинге конкурентоспособности ВЭФ (2019) // Интерфакс. Электрон. текстовые дан. - Режим доступа: https://www.interfax.ru/business/679620 (дата обращения: 15.01.2020). - Загл. с экрана.

Спартак, А. Н. Последствия цифровой трансформации для международной торговли / А. Н. Спартак // Российский внешнеэкономический вестник. - 2018. - № 5. - С. 7-23.

Степанюк, В. К. Роль конвергентных технологий в преобразовании человека и социума: потенциальные блага и риски / В. К. Степанюк // Известия Гомельского государственного университета имени Ф. Скорины. - 2017. № 4 (103). - C. 151-155.

Толкачев, С. А. Концепция циклической последовательности распространения базисных технологий в экономике и онтологическая обусловленность теорий индустриального / С. А. Толкачев, А. Ю. Тепляков // Экономическое возрождение России. - 2019. № 4 (62). - С. 19-36. 
Шваб, К. Четвертая промышленная революция / К. Шваб. - М. : Эксмо, 2016. - 208 с.

Converging Technologies for Improving Human Performance: Nanotechnology, Biotechnology, Information Technology and Cognitive Science / ed. by M. C. Roco, W. S. Bainbridge. - [S. 1.] : Springer, 2002. $-468 \mathrm{p}$.

Germany Trade\&Invest. Industrie 4.0 - Germany Market Report and Outlook. - Electronic text data. - Mode of access: https://www.gtai.de/ GTAI/Content/EN/Invest/_SharedDocs/ Downloads/GTAI/Industry-overviews/ industrie4.0-germany-market-outlook-progressreport-en.pdf. - Title from screen.

Pukala, R. Use of Neural Networks in Risk Assessment and Optimization of Insurance Cover in Innovative Enterprises / R. Pukala // Economics and Management. - 2016. - Vol. 8, № 3. - P. 43-56. DOI: https://doi.org/10.1515/emj-2016-0023.

The Industrial Internet of Things (IIoT): An Analysis Framework / H. Boyes [et al.] // Computers in Industry. - 2018. - Vol. 101. - P. 1-12. - DOI: https://doi.org/10.1016/j.compind.2018.04.015.

\section{REFERENCES}

Amatova N.E. Social'nye posledstviya vnedreniya NBIC-tekhnologij: riski i ozhidaniya [Social Consequences of the Introduction of NBICTechnologies: Risks and Expectations]. Universum: obshchestvennye nauki [Universum: Social Sciences], 2014, no. 8 (9). URL: http:// 7 universum.com/ru/social/archive/item/1549 (accessed 22 January 2020).

Arshinov V.I., Svirskij Ya.I. Slozhnostnyj mir i ego nablyudatel'. Chast' vtoraya [Complex World and Its Observer. Part Two]. Filosofiya nauki $i$ tekhniki [Philosophy of Science and Technology], 2016, vol. 21, no. 1, pp. 78-91.

Belyantsev A.E. NBIC-tekhnologii kak sfera mezhdunarodnogo vzaimodeystviya [NBICTechnologies as a Sphere of International Interaction]. Vestnik Nizhegorodskogo universiteta im. N.I. Lobachevskogo [Bulletin of the Nizhny Novgorod University], 2013, no. 6(1), pp. 350-356.

Bodrunov S.D. Noonomika: ontologicheskie tezisy [Noonomics: Ontological Theses]. Ekonomicheskoe vozrozhdenie Rossii [Economic Revival of Russia], 2019, no. 4 (62), pp. 9-16.

Buyanova M.E. Ocenka riska social'noekonomicheskogo razvitiya regionov Yuga Rossii (faktornyj podhod) [Risk Assessment of the Social and Economic Development of the Regions of the South of Russia (Factor
Approach)]. Vestnik Volgogradskogo gosudarstvennogo universiteta. Seriya 3. Ekonomika. Ecologiya [Science Journal of VolSU. Global Economic System], 2012, no. 1 (20), pp. 85-94.

Buyanova M.E. Riski razvitiya makroregional'nogo hozyajstva: vyyavlenie i regulirovanie [Risks of the Development of the Macro-Regional Economy: Identification and Regulation]. Volgograd, Izd-vo VolGU, 2007. 540 p.

Glaz'ev S.Yu. Ekonomika budushchego. Est'li u Rossii shans? [Economy of the Future. Does Russia Have a Chance?]. Moscow, Knizhnyy mir Publ., 2016. $600 \mathrm{p}$.

Global'nyj indeks innovacij: issledovanie stran $i$ regionov - 2019 [Global Innovation Index: Country and Regional Survey - 2019]. URL: https:/gtmarket.ru/ratings/global-innovationindex/info (accessed 15 December 2019).

Global'nyj innovacionnyj indeks - 2019 [Global Innovation Index 2019]. Issledovanie Vysshej shkoly ekonomiki [Research by the Higher School of Economics]. URL: https://issek.hse.ru/ news/299608238.html (accessed 20 January 2020).

Gosudarstvo. Biznes. IT 2020: Rossiya v IT-rejtingah [State. Business. IT 2020: Russia in IT Ratings]. URL: http://www.tadviser.ru/index.php/ (accessed 15 December 2019).

Data set "Bol'shie dannye sovremennoj mirovoj ekonomiki: cifrovaya platforma dlya intellektual'noj analitiki - 2020" [Date Set "Big Data of the Modern World Economy: Digital Platform for Intelligent Analytics - 2020"]. Institut nauchnyh kommunikacij [Institute of Scientific Communications]. URL: https:// www.archilab.online/data2/data-set-po-mirovojekonomike (accessed 20 January 2020).

Indeks global'noj konkurentosposobnosti (2020). Gumanitarnaya enciklopediya: Issledovaniya, Centr gumanitarnyh tekhnologij, 2006-2020 (poslednyaya redakciya: 08.02.2020) [Global Competitiveness Index (2020). Encyclopedia of Humanities: Research, Center for Humanitarian Technologies, 2006-2020 (Last Revised: February 8, 2020)]. URL: https://gtmarket.ru/ ratings/global-competitiveness-index/info (accessed 15 February 2020).

Inshakov O.V. «Yadro razvitiya» v kontekste novoj teorii faktorov proizvodstva ["The Core of Development" in the Context of the New Theory of Factors of Production]. Ekonomicheskaya nauka sovremennoj Rossii [Economic Science of Modern Russia], 2003, no. 1, pp. 11-26.

Kachalov R.M., Slepcova Yu., Shokin Ya.V. Ocenka riska realizacii innovacionnyh proektov predpriyatij s pomoshch'yu iskusstvennyh 
nejronnyh setej [Risk Assessment of Implementing Innovative Projects in Enterprises Using Artificial Neural Networks]. Vestnik Volgogradskogo gosudarstvennogo universiteta. Ekonomika [Journal of Volgograd State University. Economics], 2019, no. 4 (17), pp. 171-179.

$\mathrm{Na}$ dve strochki blizhe k budushchemu: Rossiya prodvinulas' $\mathrm{v}$ rejtinge cifrovoj konkurentosposobnosti [Two Lines Closer to the Future: Russia Has Advanced in the Ranking of Digital Competitiveness]. Kommersant, 2019, September 27 (no. 176), p. 2.

Rifkin Dzh. Tretya promyshlennaya revolyuciya: Kak gorizontalnye vzaimodejstviya menyayut energetiku, ekonomiku i mir v celom: per. s angl. [Industrial Revolution 3: How Horizontal Interactions Are Changing Energy, Economy and the World. Translated from English]. Moscow, Alpina non-fikshn Publ., 2014. 410 p.

Rossiya sohranila 43-e mesto $v$ rejtinge konkurentosposobnosti VEF (2019) [Russia Retained $43^{\text {rd }}$ Place in the WEF Competitiveness Rating (2019)]. Interfaks. URL: https://www. interfax.ru/business/679620 (accessed 15 January 2020).

Spartak A.N. Posledstviya cifrovoj transformacii dlya mezhdunarodnoj torgovli [Consequences of Digital Transformation for International Trade]. Rossijskij vneshneekonomicheskij vestnik [Russian Foreign Economic Bulletin], 2018, no. 5 , pp. 7-23.

Stepanyuk V.K. Rol' konvergentnyh tekhnologij v preobrazovanii cheloveka i sociuma: potencial'nye blaga i riski [The Role of Convergent Technologies in the Transformation of Man and Society: Potential Benefits and Risks]. Izvestiya Gomel'skogo gosudarstvennogo universiteta imeni F. Skoriny [Bulletin of the F. Skorina Gomel State University], 2017, no. 4 (103), pp. 151-155.

Tolkachev S.A., Teplyakov A.Yu. Koncepciya ciklicheskoj posledovatel'nosti rasprostraneniya bazisnyh tekhnologij $\mathrm{v}$ ekonomike i ontologicheskaya obuslovlennost teorij industrial'nogo [The Concept of a Cyclical Sequence of the Spread of Basic Technologies in the Economy and the Ontological Conditionality of Theories of the Industrial]. Ekonomicheskoe vozrozhdenie Rossii [Economic Revival of Russia], 2019, no. 4 (62), pp. 19-36.

Shvab K. Chetvertaya promyshlennaya revolyuciya [The Fourth Industrial Revolution]. Moscow, Eksmo Publ., 2016. 208 p.

Roco M.C., Bainbridge W.S., eds. Converging Technologies for Improving Human Performance: Nanotechnology, Biotechnology, Information Technology and Cognitive Science. [S. 1.], Springer, 2002. 468 p.

Germany Trade\&Invest. Industrie 4.0 - Germany Market Report and Outlook. URL: https://www. gtai.de/GTAI/Content/EN/Invest/_SharedDocs/ Downloads/GTAI/Industry-overviews/ industrie4.0-germany-market-outlook-progressreport-en.pdf.

Pukala R. Use of Neural Networks in Risk Assessment and Optimization of Insurance Cover in Innovative Enterprises. Economics and Management, 2016, vol. 8, no. 3, pp. 43-56. DOI: https://doi.org/10.1515/emj-2016-0023.

Boyes H., Hallaq B., Cunningham J., Watson T. The Industrial Internet of Things (IIoT): An Analysis Framework. Computers in Industry, 2018, vol. 101,pp. 1-12. DOI: https://doi.org/10.1016/ j.compind.2018.04.015.

\section{Information About the Author}

Marina E. Buyanova, Doctor of Sciences (Economics), Professor, Head of the Department of Economic Theory, World and Regional Economy, Volgograd State University, Prosp. Universitesky, 100, 400062 Volgograd, Russian Federation, buyanovam@rambler.ru, https://orcid.org/0000-0003-1052-3780

\section{Информация об авторе}

Марина Эдуардовна Буянова, доктор экономических наук, профессор, заведующая кафедрой экономической теории, мировой и региональной экономики, Волгоградский государственный университет, просп. Университетский, 100, 400062 г. Волгоград, Российская Федерация, buyanovam@rambler.ru,https://orcid.org/0000-0003-1052-3780 